\title{
ANALISIS STATISTIK MENGHITUNG KUALITAS LAYANAN AKADEMIK TERHADAP KEPUASAN MAHASISWA MEMBENTUK LOYALITAS MAHASISWA
}

\author{
Tantri Wahyuni \\ Program Studi Informatika, Fakultas Teknik, Universitas Majalengka \\ email: Tantriwah@gmail.com
}

\begin{abstract}
The purpose of this research is to analyze how the dimensions of academic service quality had a significant positive effect on student satisfaction which in turn provide significant positive impact on student loyalty. The role of media intervening: student satisfaction on student loyalty is expected to be confirmed. This research uses non-probability sampling method with purposive technique. The instrument of this research use questionnaire that analyzed by Structural Equation Modelling: Amos 22. From the analysis of the research, model tested shows that the model is fit and can be accepted based on the indices of the model with the RMSEA of 0,073. The results of this research indicate that the Five dimensions of Reliability, Assurance, Tangibles, Empathy and Responsiveness have a positive influence on the Quality of Academic Service. And there is a positive effect of Academic Service Quality on Student Satisfaction in the form of student loyalty.
\end{abstract}

Keywords: Academic Service Quality, Customer Satisfaction, Student Loyalty, Amos 22

\section{PENDAHULUAN}

Layanan dalam bidang pendidikan dan kesehatan merupakan barometer pembangunan ekonomi, sosial dan budaya suatu bangsa (Alves and Raposo, 2010) sehingga kualitas pendidikan tinggi akan berpengaruh besar pada perkembangan ekonomi regional dan nasional (Rosca et al, 2008). Karena tuntutan tersebut sangat dimungkinkan sektor pendidikan tinggi akan beralih fokus menuju orientasi pasar yang menerapkan mekanisme pasar seperti industri-industri lainnya sehingga sektor pendidikan tinggi harus mampu mempertahankan keberadaannya dengan cara meningkatkan kualitas layanan akademik dan kepuasan mahasiswanya. Meskipun banyak penekanan pada penjaminan mutu sistem pendidikan dengan ditetapkannya berbagai standar pendidikan tinggi, tetap saja tidak ada konsensus yang dapat dicapai lebih dalam lagi dari definisi kualitas pendidikan tinggi karena tidak ada alat yang unik untuk mengukurnya (Sarbu et al, 2009). Di sisi lain, terdapat konsensus hubungan positif antara persepsi kualitas layanan pendidikan dan kepuasan mahasiswa (Alves dan Raposo, 2010; Ham dan Hayduk, 2003; Farahmandian et al, 2013). Perusahaan spesialis pengukur kepuasan pelanggan dalam industri otomotif, membuktikan bahwa perusahaan yang berhasil meningkatkan kepuasan pelanggan dalam jangka waktu lima tahun (19992004) mengalami kenaikan nilai bagi pemegang sahamnya sebesar $+52 \%$. Sebaliknya, perusahaan yang mengalami penurunan nilai kepuasan pelanggan, pemegang sahamnya juga mengalami penurunan nilai sebesar $-28 \%$. Demkian halnya dengan penelitian yang dilakukan oleh Dwi Aryani dan Febrina Rosinta (2010), terdapat pengaruh yang kuat antara kualitas layanan terhadap kepuasan pelanggan. Dalam penelitian ini diharapkan pengaruh dari kelima dimensi pembentuk kualitas layanan terhadap kepuasan mahasiswa terbukti. 


\section{METODE PENELITIAN \\ 2.1. Rancangan Kegiatan}

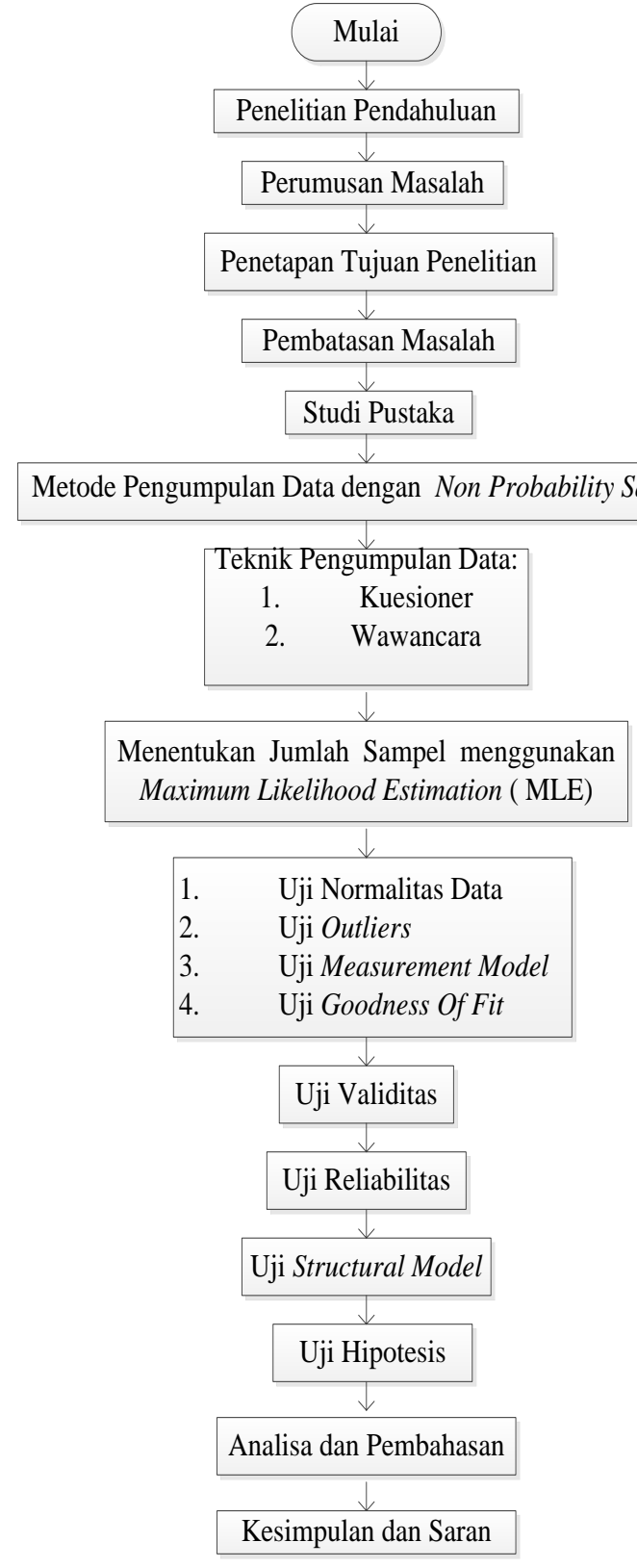

Gambar 1. Rancangan Kegiatan.

\subsection{Teknik Pengumpulan Data}

Menggunakan teknik survei melalui kuesioner dengan skala Likert 1 s/d 5 dan wawancara.

\subsection{Teknik Analisis Data}

Menggunakan Software Analysis Moment Of Structural ( AMOS ) v-22.
Jurnal J-Ensitec: Vol 04|No. 01, November 2017

\section{HASIL DAN PEMBAHASAN \\ 3.1. Uji Measurement Model}

Tujuan pengujian adalah untuk mengetahui seberapa tepat variable-variabel manifes dapat menjelaskan variabel laten yang ada. Hasilnya ditunjukkan pada gambar 2 .

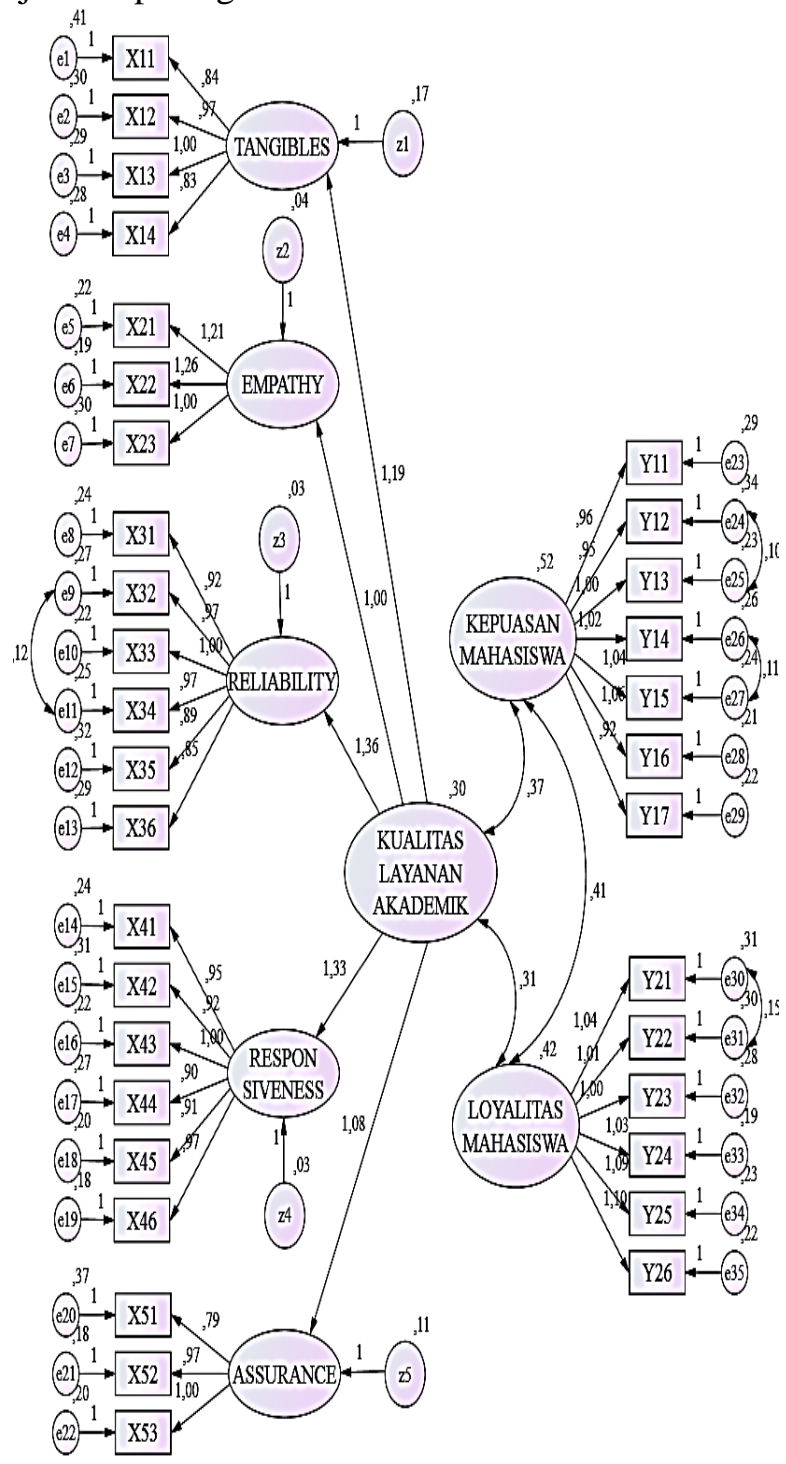

Gambar 2. Uji Measurement Model.

\subsection{Uji Goodness of Fit}

Hasil perhitungan model SEM menghasilkan indeks goodness of fit sebagaimana ditunjukkan pada table 1. Pengujian ini dapat dikatakan fit. Karena sebagian besar hasil pengujian menghasilkan nilai Good fit dan marginal fit. 
Jurnal J-Ensitec: Vol 04|No. 01, November 2017

Tabel 1. Hasil Uji Goodness Of Fit.

\begin{tabular}{|c|c|c|c|}
\hline Kriteria & $\begin{array}{c}\text { Hasil } \\
\text { Model }\end{array}$ & $\begin{array}{c}\text { Nilai } \\
\text { Kritis }\end{array}$ & Kesimpulan \\
\hline Probability & 0,00 & $\geq 0,05$ & Acceptable \\
\hline CMIN/DF & 2,852 & $\begin{array}{c}0,08- \\
2,00\end{array}$ & Acceptable \\
\hline RMSEA & 0,073 & $<0,05$ & Good fit \\
\hline AGFI & 0,763 & $>0,8$ & Marginal fit \\
\hline PNFI & 0,80 & $\begin{array}{c}0,60- \\
0,90\end{array}$ & Good fit \\
\hline CFI & 0,91 & $\geq 0,90$ & Good fit \\
\hline TLI & 0,902 & $\geq 0,90$ & Good fit \\
\hline
\end{tabular}

\subsection{Uji Validitas}

Berdasarkan tabel 2 ,ternyata semua nilai loading factor dari tiap indikator $>0,50$, sehingga indikatorindikator yang dipakai dalam penelitian ini telah memenuhi syarat untuk menjadi indikator konstruk dari kualitas layanan akademik, kepuasan, dan loyalitas mahasiswa.

Tabel.2 Nilai Loading Factor

\begin{tabular}{|c|c|c|c|}
\hline Konstruk & Indikator & Kode & $\begin{array}{c}\text { Loading } \\
\text { Factor }\end{array}$ \\
\hline $\begin{array}{l}\text { Tangi } \\
\text { bles }\end{array}$ & $\begin{array}{l}\text { Ketersediaa } \\
\mathrm{n} \text { parkir } \\
\text { Ketersediaa } \\
\mathrm{n} \\
\text { laboratoriu } \\
\mathrm{m} \\
\text { Ketersediaa } \\
\mathrm{n} \text { komputer } \\
\text { untuk } \\
\text { administras } \\
\mathrm{i} \\
\text { Ketersediaa } \\
\text { n ruangan, } \\
\text { meja, kursi }\end{array}$ & $\begin{array}{l}\mathrm{X}_{11} \\
\mathrm{x}_{12} \\
\mathrm{X}_{13}\end{array}$ & $\begin{array}{l}0,711 \\
0,810 \\
0,819 \\
0,772\end{array}$ \\
\hline Empathy & $\begin{array}{l}\text { Informasi } \\
\text { perkuliahan } \\
\text { oleh dosen } \\
\text { Pengembali } \\
\text { an hasil } \\
\text { evaluasi/tes } \\
\text { oleh dosen } \\
\text { Keadaan } \\
\text { Meja-Kursi }\end{array}$ & $\begin{array}{l}\mathrm{x}_{21} \\
\mathrm{x}_{22}\end{array}$ & $\begin{array}{l}0,834 \\
0,858 \\
0,730\end{array}$ \\
\hline
\end{tabular}

\begin{tabular}{|c|c|c|c|}
\hline $\begin{array}{l}\text { Reliabi } \\
\text { lity }\end{array}$ & $\begin{array}{l}\text { Profesional } \\
\text { isme } \\
\text { staf/karyaw } \\
\text { an } \\
\text { Keramahan } \\
\text { staf/karyaw } \\
\text { an } \\
\text { Kenyamana } \\
\text { n dalam } \\
\text { pelayanan } \\
\text { Kesopanan } \\
\text { staf } \\
\text { Kejelasan } \\
\text { pemberian } \\
\text { informasi } \\
\text { oleh staf } \\
\text { Akurasi } \\
\text { perhitungan } \\
\text { nilai pada } \\
\text { KHS }\end{array}$ & $\begin{array}{l}x_{31} \\
x_{32} \\
x_{33} \\
x_{34} \\
x_{35} \\
x_{36}\end{array}$ & $\begin{array}{c}0,826 \\
0,823 \\
0,855 \\
0,831 \\
0,772 \\
0,774\end{array}$ \\
\hline $\begin{array}{l}\text { Respon- } \\
\text { siveness }\end{array}$ & $\begin{array}{l}\text { Respon } \\
\text { karyawan } \\
\text { Kecepatan } \\
\text { pelayanan } \\
\text { Daya } \\
\text { tanggap } \\
\text { karyawan } \\
\text { Kehadiran } \\
\text { karyawan } \\
\text { Ketepatan } \\
\text { pelaksanaa } \\
\text { n janji } \\
\text { pelayanan } \\
\text { Kesabaran } \\
\text { karyawan }\end{array}$ & $\begin{array}{l}\mathrm{x}_{41} \\
\mathrm{x}_{42} \\
\mathrm{x}_{43} \\
\mathrm{x}_{44} \\
\mathrm{X}_{45}\end{array}$ & $\begin{array}{l}0,824 \\
0,780 \\
0,847 \\
0,795 \\
0,835 \\
\\
0,867\end{array}$ \\
\hline $\begin{array}{l}\text { Assuran } \\
\text { ce }\end{array}$ & $\begin{array}{l}\text { Kebersihan } \\
\text { ruang } \\
\text { kuliah } \\
\text { Ketepatan } \\
\text { jadwal } \\
\text { penerimaan } \\
\text { beasiswa } \\
\text { Kesesuaian } \\
\text { penerima } \\
\text { beasiswa } \\
\text { dengan } \\
\text { syarat } \\
\text { penerimaan }\end{array}$ & $\begin{array}{l}\mathrm{X}_{51} \\
\mathrm{x}_{52} \\
\mathrm{X}_{53}\end{array}$ & $\begin{array}{l}0,661 \\
0,839 \\
0,836\end{array}$ \\
\hline
\end{tabular}


Jurnal J-Ensitec: Vol 04|No. 01, November 2017

\begin{tabular}{|c|c|c|c|}
\hline $\begin{array}{l}\text { Kepua } \\
\text { san pada } \\
\text { harga }\end{array}$ & $\begin{array}{l}\text { Puas atas } \\
\text { fasilitas } \\
\text { laboratoriu } \\
\mathrm{m} \\
\text { Puas atas } \\
\text { biaya } \\
\text { kuliah } \\
\text { Puas atas } \\
\text { kejujuran } \\
\text { menetapka } \\
\text { n biaya } \\
\text { yang timbul } \\
\text { selama } \\
\text { perkuliahan }\end{array}$ & $\begin{array}{l}Y_{11} \\
Y_{12} \\
Y_{13}\end{array}$ & $\begin{array}{l}0,789 \\
0,760 \\
0,830\end{array}$ \\
\hline $\begin{array}{l}\text { Kepua } \\
\text { san Fungsio } \\
\text { nal }\end{array}$ & $\begin{array}{l}\text { Puas atas } \\
\text { perkuliahan } \\
\text { Puas atas } \\
\text { dosen } \\
\text { pengampu } \\
\text { Puas atas } \\
\text { kenyamana } \\
\text { n } \\
\text { lingkungan } \\
\text { kampus } \\
\text { Puas atas } \\
\text { layanan } \\
\text { bantuan }\end{array}$ & $\begin{array}{l}\mathrm{Y}_{14} \\
\mathrm{Y}_{15} \\
\mathrm{Y}_{16} \\
\mathrm{Y}_{17}\end{array}$ & $\begin{array}{l}0,819 \\
0,838 \\
0,856 \\
0,817\end{array}$ \\
\hline $\begin{array}{l}\text { Cogniti } \\
\text { ve loyalty }\end{array}$ & $\begin{array}{l}\text { Semangat } \\
\text { untuk } \\
\text { melaksanak } \\
\text { an } \\
\text { perkuliahan } \\
\text { Selalu } \\
\text { mengerjaka } \\
\text { n tugas dan } \\
\text { mengumpul } \\
\text { kannya } \\
\text { tepat waktu }\end{array}$ & $\mathrm{Y}_{21}$ & $\begin{array}{l}0,769 \\
0,767\end{array}$ \\
\hline $\begin{array}{l}\text { Affective } \\
\text { loyalty }\end{array}$ & $\begin{array}{l}\text { Senang } \\
\text { memanfaat } \\
\text { kan fasilitas } \\
\text { kampus } \\
\text { Senang atas } \\
\text { perkuliahan } \\
\text { yang } \\
\text { selama ini } \\
\text { sedang } \\
\text { berlangsun } \\
\text { g }\end{array}$ & $\mathrm{Y}_{23}$ & $\begin{array}{l}0,777 \\
0,835\end{array}$ \\
\hline
\end{tabular}

\begin{tabular}{|c|c|c|c|}
\hline $\begin{array}{l}\text { Conati } \\
\text { ve loyalty }\end{array}$ & $\begin{array}{l}\text { Mereferens } \\
\text { ikan pada } \\
\text { teman } \\
\text { untuk } \\
\text { kuliah di } \\
\text { kampus } \\
\text { saat ini }\end{array}$ & $\mathrm{Y}_{25}$ & 0,826 \\
\hline $\begin{array}{l}\text { Action } \\
\text { loyalty }\end{array}$ & $\begin{array}{l}\text { Semangat } \\
\text { untuk } \\
\text { menjelaska } \\
\text { n kepada } \\
\text { rekan dan } \\
\text { kerabat } \\
\text { tentang } \\
\text { segala } \\
\text { keuntungan } \\
\text { selama } \\
\text { kuliah di } \\
\text { kampus ini }\end{array}$ & $\mathrm{Y}_{26}$ & 0,834 \\
\hline
\end{tabular}

Dalam tabel 3 terlihat bahwa dimensi yang terkuat dalam menjelaskan kualitas layanan berturut-turut yakni reliability, responsiveness, empathy, assurance dan tangibles. Hal ini senada dengan penelitian Berry (1991) yang menyimpulkan bahwa diantara kelima dimensi penentu kualitas berdasarkan nilai pentingnya menurut pelanggan, reliability secara konsisten merupakan dimensi yang paling kritis, selanjutnya secara berturut-turut adalah responsiveness, empathy, assurance dan tangibles.

Tabel 3. Nilai Loading Factor Dimensi dalam Kualitas Layanan.

\begin{tabular}{lll}
\hline Konstruk & Dimensi & $\begin{array}{l}\text { Loading } \\
\text { Factor }\end{array}$ \\
\hline Kualitas & Reliability & 0,973 \\
Layanan & Responsiveness & 0,971 \\
Akademik & Empathy & 0,943 \\
& Assurance & 0,871 \\
& Tangibles & 0,847 \\
\hline
\end{tabular}

\subsection{Uji Reliabilitas}

Hasil perhitungan construct reliability untuk setiap konstruk disajikan pada tabel 4. Construct reliability di atas 0,70 menunjukkan reliabilitas yang baik.

Pada proses standardisasi, diperoleh angka korelasi seperti pada tabel 5. Tingginya angka korelasi $(>0,5)$ antara konstruk menunjukkan adanya hubungan 
Jurnal J-Ensitec: Vol 04|No. 01, November 2017

yang erat dan memiliki hubungan yang positif dan searah.

Variasi indikator dari Squared Multiple Correlations. Tabel 6 dapat dijelaskan bahwa koefisien determinasi yang paling besar diantara lima dimensi kualitas layanan dijelaskan oleh variabilitas reliability sebesar 97,3\%. Sedangkan koefisien determinasi yang paling besar diantara indikator dijelaskan oleh variabilitas x46 sebesar 86,7\%.

Tabel. 4 Hubungan Konstruk Berdasarkan Covariance

\begin{tabular}{|c|c|c|c|}
\hline & & \multicolumn{2}{|c|}{ Estimate S.E. C.R. P } \\
\hline $\begin{array}{l}\text { LOYALITAS } \\
\text { MAHASISW }\end{array}$ & $\begin{array}{l}\text { KUALITAS } \\
\text { LAYANAN } \\
\text { AKADEMIK }\end{array}$ & ,308 & ,034 9,096*** \\
\hline $\begin{array}{l}\text { KEPUASAN } \\
\text { MAHASISW }\end{array}$ & $\begin{array}{l}\text { KUALITAS } \\
\text { LAYANAN } \\
\text { AKADEMIK }\end{array}$ & ,366 & ,038 9,597 *** \\
\hline $\begin{array}{l}\text { LOYALITAS } \\
\text { MAHASISW }\end{array}$ & $\begin{array}{l}\text { KEPUASAN } \\
\text { MAHASISW }\end{array}$ & ,411 & $, 0419,928 * * *$ \\
\hline
\end{tabular}

Sumber: Hasil Pengolahan data dengan Amos 22.

Tabel 5. Korelasi Antar Konstruk.

\begin{tabular}{llr}
\hline & & Estimate \\
\hline LOYALITAS & KUALITAS & \\
MAHASISWA & $<->$ LAYANAN &, 865 \\
& AKADEMIK & \\
KEPUASAN & KUALITAS & \\
MAHASISWA & $<-$ LAYANAN &, 925 \\
& AKADEMIK & \\
LOYALITAS & KEPUASAN &, 881 \\
MAHASISWA & K--> & MAHASISWA \\
\hline
\end{tabular}

Sumber: Hasil Pengolahan data dengan Amos 22.

Tabel 6. Squared Multiple Correlations.

\begin{tabular}{||l|l|l|l|}
\hline \hline & & & Estimate \\
\hline \hline RELIABILITY & $<---$ & $\begin{array}{l}\text { KUALITAS } \\
\text { LAYANAN } \\
\text { AKADEMIK }\end{array}$ &, 973 \\
\hline \hline EMPATHY & $<$ & $\begin{array}{l}\text { KUALITAS } \\
\text { LAYANAN } \\
\text { AKADEMIK }\end{array}$ &, 943 \\
\hline \hline TANGIBLES & $<$ & $\begin{array}{l}\text { KUALITAS } \\
\text { LAYANAN } \\
\text { AKADEMIK }\end{array}$ &, 847 \\
\hline \hline ASSURANCE & $<---$ & $\begin{array}{l}\text { KUALITAS } \\
\text { LAYANAN } \\
\text { AKADEMIK }\end{array}$ \\
\hline
\end{tabular}

Computer Science | Industrial Engineering |Mechanic Engineering | Civil Engineering

\begin{tabular}{|c|c|c|c|}
\hline & & & Estimate \\
\hline $\begin{array}{l}\text { RESPON- } \\
\text { SIVENESS }\end{array}$ & $<--$ & \begin{tabular}{|l} 
KUALITAS \\
LAYANAN \\
AKADEMIK
\end{tabular} & ,971 \\
\hline $\mathrm{X} 13$ & $<-$ & TANGIBLES & ,819 \\
\hline $\mathrm{X} 12$ & <-- & TANGIBLES & ,810 \\
\hline $\mathrm{X} 11$ & <-- & TANGIBLES & ,711 \\
\hline $\mathrm{X} 23$ & <-- & EMPATHY & ,730 \\
\hline $\mathrm{X} 22$ & <-- & EMPATHY & ,858 \\
\hline $\mathrm{X} 21$ & $<-$ & EMPATHY & ,834 \\
\hline $\mathrm{X} 33$ & $<--$ & RELIABILITY & 855 \\
\hline $\mathrm{X} 32$ & <-- & RELIABILITY & ,823 \\
\hline $\mathrm{X} 31$ & <-- & RELIABILITY & ,826 \\
\hline $\mathrm{X} 43$ & $<--$ & $\begin{array}{l}\text { RESPON- } \\
\text { SIVENESS } \\
\end{array}$ &, 847 \\
\hline X42 & $<--$ & \begin{tabular}{|l|} 
RESPON- \\
SIVENESS \\
\end{tabular} &, 780 \\
\hline $\mathrm{X} 41$ & $<--$ & \begin{tabular}{|l} 
RESPON- \\
SIVENESS \\
\end{tabular} &, 824 \\
\hline $\mathrm{X} 53$ & <-- & ASSURANCE & ,836 \\
\hline $\mathrm{X} 52$ & <-- & ASSURANCE & ,839 \\
\hline $\mathrm{X} 51$ & $<--$ & ASSURANCE & ,661 \\
\hline Y23 & $<--$ & $\begin{array}{l}\text { LOYALITAS } \\
\text { MAHASISWA }\end{array}$ & ,777 \\
\hline Y22 & $<--$ & \begin{tabular}{|l} 
LOYALITAS \\
MAHASISWA
\end{tabular} & ,767 \\
\hline Y21 & $<--$ & \begin{tabular}{|l} 
LOYALITAS \\
MAHASISWA
\end{tabular} & ,769 \\
\hline Y13 & $<---$ & $\begin{array}{l}\text { KEPUASAN } \\
\text { MAHASISWA }\end{array}$ &, 830 \\
\hline Y12 & $<--$ & $\begin{array}{l}\text { KEPUASAN } \\
\text { MAHASISWA }\end{array}$ & ,760 \\
\hline Y11 & $<--$ & \begin{tabular}{|l|} 
KEPUASAN \\
MAHASISWA
\end{tabular} & ,789 \\
\hline $\mathrm{X} 14$ & <-- & TANGIBLES & ,772 \\
\hline $\mathrm{X} 34$ & <-- & RELIABILITY & ,831 \\
\hline $\mathrm{X} 35$ & <-- & RELIABILITY & ,772 \\
\hline $\mathrm{X} 36$ & $<-$ & RELIABILITY & ,774 \\
\hline $\mathrm{X} 44$ & $<--$ & \begin{tabular}{|l|} 
RESPON- \\
SIVENESS \\
\end{tabular} &, 795 \\
\hline $\mathrm{X} 45$ & $<--$ & $\begin{array}{l}\text { RESPON- } \\
\text { SIVENESS }\end{array}$ &, 835 \\
\hline $\mathrm{X} 46$ & $<--$ & \begin{tabular}{|l|} 
RESPON- \\
SIVENESS \\
\end{tabular} & ,867 \\
\hline Y14 & $<--$ & \begin{tabular}{|l|} 
KEPUASAN \\
MAHASISWA \\
\end{tabular} & ,819 \\
\hline
\end{tabular}




\begin{tabular}{|c|c|c|c|}
\hline & & & Estimate \\
\hline Y15 & $<--$ & $\begin{array}{l}\text { KEPUASAN } \\
\text { MAHASISWA }\end{array}$ & ,838 \\
\hline Y16 & $<--$ & $\begin{array}{l}\text { KEPUASAN } \\
\text { MAHASISWA }\end{array}$ & ,856 \\
\hline Y17 & $<--$ & $\begin{array}{l}\text { KEPUASAN } \\
\text { MAHASISWA }\end{array}$ & ,817 \\
\hline Y24 & $<--$ & $\begin{array}{l}\text { LOYALITAS } \\
\text { MAHASISWA }\end{array}$ & ,835 \\
\hline Y25 & $<--$ & $\begin{array}{l}\text { LOYALITAS } \\
\text { MAHASISWA }\end{array}$ & ,826 \\
\hline Y26 & $<--$ & $\begin{array}{l}\text { LOYALITAS } \\
\text { MAHASISWA }\end{array}$ & ,834 \\
\hline
\end{tabular}

Sumber: Hasil Pengolahan data dengan Amos 22, 2017.

\subsection{Uji Structural Model}

Hasil Estimasi pada tabel 7 didapatkan nilai estimate antar konstruk dan konstruk dengan dimensi. Sehingga didapat persamaan struktural sebagai berikut. Pertama, tangibles $=0,847 \mathrm{KL}$. Kedua, empathy $=0,943 \mathrm{KL}$. Ketiga, reliability $=0,973 \mathrm{KL}$. Keempat, responsiveness $=0,971 \mathrm{KL}$. Kelima, assurance $=0,871 \mathrm{KL}$. Keenam, kepuasan mahasiswa $=0,925 \mathrm{KL}$. Artinya, pengaruh kualitas layanan akademik (KL) terhadap kepuasan mahasiswa bernilai positif dan signifikan. Ini berarti bahwa semakin baik kualitas layanan akademik yang diberikan kampus, maka semakin besar kepuasan mahasiswa. Ketujuh, loyalitas mahasiswa $=0,865 \mathrm{KL}+0,881 \mathrm{KP}$. Artinya, pengaruh kualitas layanan akademik (KL) terhadap loyalitas bernilai positif, bahwa semakin baik kualitas layanan pada kampus, maka mahasiswa akan semakin loyal.

Tabel 7. Tabel Estimasi Parameter.

\begin{tabular}{|c|c|c|}
\hline & & Estimate \\
\hline RELIABILITY & $\begin{array}{ll} & \text { KUALITAS } \\
& \text { LAYANAN } \\
& \text { AKADEMIK }\end{array}$ & 0,973 \\
\hline EMPATHY & $\begin{aligned} & \text { KUALITAS } \\
& \leftarrow \text { LAYANAN } \\
& \text { AKADEMIK }\end{aligned}$ & 0,943 \\
\hline TANGIBLES & $\begin{aligned} & \text { KUALITAS } \\
\leftarrow & \text { LAYANAN } \\
& \text { AKADEMIK }\end{aligned}$ & 0,847 \\
\hline ASSURANCE & $\begin{aligned} & \text { KUALITAS } \\
& \leftarrow \text { LAYANAN } \\
& \text { AKADEMIK }\end{aligned}$ & 0,871 \\
\hline $\begin{array}{l}\text { RESPON- } \\
\text { SIVENESS }\end{array}$ & $\begin{aligned} & \text { KUALITAS } \\
\leftarrow & \text { LAYANAN } \\
& \text { AKADEMIK }\end{aligned}$ & 0,971 \\
\hline LOYALITAS & $\leftrightarrow$ KUALITAS & 0,865 \\
\hline
\end{tabular}

Jurnal J-Ensitec: Vol 04|No. 01, November 2017

\begin{tabular}{|c|c|c|}
\hline MAHASISWA & $\begin{array}{l}\text { LAYANAN } \\
\text { AKADEMIK }\end{array}$ & \\
\hline $\begin{array}{l}\text { KEPUASAN } \\
\text { MAHASISWA }\end{array}$ & $\begin{aligned} & \text { KUALITAS } \\
\leftrightarrow & \text { LAYANAN } \\
& \text { AKADEMIK }\end{aligned}$ & 0,925 \\
\hline $\begin{array}{l}\text { LOYALITAS } \\
\text { MAHASISWA }\end{array}$ & $\leftrightarrow \begin{array}{l}\text { KEPUASAN } \\
\text { MAHASISWA }\end{array}$ & 0,881 \\
\hline
\end{tabular}

\subsection{Pengujian Hipotesis}

Hasil pengujian terhadap hipotesis yang diajukan dalam penelitian ini secara ringkas ditunjukkan pada tabel 8. Uji signifikansi bila disangkutkan dengan aktual penelitian ini, maka:

1. Semakin tinggi kualitas layanan akademik, semakin tinggi kepuasan mahasiswa. Diperoleh, C. $R=9,597$ dan estimasi parameter $=0,925$, maka

\section{Hipotesa Diterima.}

Pada pengujian hipotesis I digunakan taraf signifikansi 5\%, hal tersebut digunakan karena C.R $\geq 1,96$. Parameter estimasi antara variabel kualitas layanan dengan kepuasan pelanggan menunjukkan hasil signifikan dengan nilai $\mathrm{C} . \mathrm{R}=$ 9,597 dengan nilai probabilitas <0,05. Dengan demikian, Hipotesis I dapat dibuktikan.

Semakin tinggi kualitas layanan akademik, semakin tinggi kepuasan mahasiswa. Oleh karena itu, Universitas Majalengka harus meningkatkan kualitas layanan melebihi pesaingnya. Misalnya: ketersediaan lapangan parkir yang memadai, fasilitas laboratorium yang lengkap untuk semua mata kuliah praktikum, kebersihan ruang kuliah serta kecepatan pelayanan oleh staf/karyawan

2. Semakin tinggi kualitas layanan akademik, semakin tinggi loyalitas mahasiswa. Diperoleh, C. $R=9,096$ dan estimasi parameter $=0,865$, maka

\section{Hipotesa Diterima.}

Pada pengujian hipotesis II digunakan taraf signifikansi 5\%, hal tersebut digunakan karena C.R $\geq 1,96$. Parameter estimasi antara variabel kualitas layanan dengan kepuasan pelanggan menunjukkan hasil signifikan dengan nilai C.R = 9,096 dengan nilai probabilitas <0,05. Dengan demikian, Hipotesis II dapat dibuktikan. 
Semakin tinggi kualitas layanan akademik, semakin tinggi loyalitas mahasiswa. Loyalitas akan tercipta jika profesionalisme staf/karyawan meningkat, fasilitas laboratorium dilengkapi serta informasi perkuliahan oleh

3. Semakin tinggi kepuasan mahasiswa, semakin tinggi loyalitas mahasiswa. Diperoleh, C.R = 9,928 dan estimasi parameter $=0,881$, maka

\section{Hipotesa Diterima.}

Pada pengujian hipotesis III digunakan taraf signifikansi 5\%, hal tersebut digunakan karena C.R $\geq 1,96$. Parameter estimasi antara variabel kualitas layanan dengan kepuasan pelanggan menunjukkan hasil signifikan dengan nilai C.R = 9,928 dengan nilai probabilitas $<0,05$. Dengan demikian, Hipotesis III dapat dibuktikan.

Semakin tinggi tingkat kepuasan mahasiswa, semakin tinggi loyalitas mahasiswa. Kepuasan mahasiswa atas dosen pengampu, kepuasan mahasiswa atas kenyamanan lingkungan kampus akan membuat mahasiswa semangat untuk melaksanakan perkuliahan, sehingga mahasiswa semangat untuk menjelaskan kepada rekan dan sahabat tentang segala keuntungan jika kuliah di kampus ini.

\section{KESIMPULAN}

Hasil penelitian menunjukkan bahwa kelima dimensi pembentuk kualitas layanan terbukti berpengaruh secara signifikan terhadap kualitas layanan. Dimensi terkuat dalam menjelaskan kualitas layanan berturut-turut adalah reliability, responsiveness, empathy, assurance dan tangibles. Hasil penelitian ini juga diperoleh bahwa: 1) Kualitas layanan akademik berpengaruh positif terhadap kepuasan mahasiswa. Ini dibuktikan dengan nilai korelasi antar konstruk sebesar: 0,925. 2) Kualitas layanan akademik berpengaruh positif terhadap loyalitas mahasiswa. Ini dibuktikan dengan nilai korelasi antar konstruk sebesar: 0,865. 3) Kepuasan mahasiswa berpengaruh positif terhadap loyalitas mahasiswa. Ini dibuktikan dengan nilai korelasi antar konstruk sebesar: 0,881

\section{REFERENSI}

Alves H and Raposo M 2010 The influence of University Image on Student Behaviour International Journal of Educational Management 24 (1) : 73-85

Dwi Aryani dan Febri Rosinta 2010 Pengaruh Kualitas Layanan Terhadap Kepuasan Pelanggan Dalam Membentuk Loyalitas Jurnal Ilmu Administrasi dan Organisasi 17 (2)

Farahmandian S, Minavand $\mathrm{H}$ and Afshardost $\mathrm{M}$ 2013 Perceived Service Quality and Student Satisfaction in Higher Education IOSR Journal of Business and Management $12: 65-74$

Ham L and Hayduk S 2003 Gaining competitive advantage in higher education: analyzing the gap between expectations and perceptions of service quality International Journal of Value-Based Management $16: 223-242$ 